\title{
Effect of Different Sowing Media on Seed Germination and Seedling Growth of (Golden Shower Tree) Senna fistula L
}

\section{1*MAJEKODUNMI, OA; ${ }^{2}$ ABIOLA, IO; ${ }^{3}$ ADEREMI, AM; ${ }^{3}$ ADEDIPE, JO; ${ }^{4}$ OGUNWALE, OG; ${ }^{5}$ OYEWOLE, OO}

\author{
${ }^{* 1}$ Horticulture and Landscape Technology Department, Federal College of Forestry, Ibadan, Nigeria \\ ${ }^{2}$ Forestry Research Institute of Nigeria, Ibadan, Nigeria. \\ ${ }^{3}$ Agricultural Technology Department, Federal College of Forestry, Ibadan, Nigeria \\ ${ }^{4}$ Lecturer, Agricultural Extension and Management Department, Federal College of Forestry, Ibadan, Nigeria \\ *Corresponding Author Email: aderemi.am@frin.gov.ng; Tel: 08035637542, 08079713340
}

\begin{abstract}
ABSTARCT: This study investigated the effect of sowing media on the seed germination and subsequent seedling growth of Senna fistula L. Treatments were T1 (Top soil), T2 (River sand), T3 (Grinded coconut husk) and T4 (weathered sawdust), replicated two times for seed germination. The treatments were arranged in a Completely Randomized Design (CRD) and the data generated was subjected to analysis of variance (ANOVA) at $\%$ level of significance, while mean separation where appropriate was done using Least Significant Difference (LSD). The different sowing media used had positive effect on the seed emergence, the seeds planted in river sand had the highest emergence percentage of $70 \%$. The different sowing media used did not have any significant effect on the vegetative growth parameters, statistically, they had same effect on the parameters measured. Nonetheless, seedlings from river sand produced highest number of leave (20.4), seedlings from topsoil produced highest plant height and largest leaf area of $10.62 \mathrm{~cm}$ and $37.14 \mathrm{~cm}^{2}$ respectively. The seedlings from weathered sawdust produced the highest stem diameter of $0.79 \mathrm{~mm}$, while seedlings from grinded coconut husk had lowest values for all the growth parameters measured. Therefore, it is recommended that river sand or weathered sawdust can be used to propagate Senna fistula seeds.
\end{abstract}

\section{DOI: https://dx.doi.org/10.4314/jasem.v25i8.32}

Copyright: Copyright $(02021$ Majekodunmi et al. This is an open access article distributed under the Creative Commons Attribution License (CCL), which permits unrestricted use, distribution, and reproduction in any medium, provided the original work is properly cited.

Dates: Received: 10 May 2021; Revised: 28 June 2021; Accepted: 01 July 2021

Keywords: Seed germination, Top soil, River sand, Grinded coconut husk, weathered sawdust

Senna fistula $\mathrm{L}$. is an ornamental and medicinal deciduous tree commonly called "golden shower tree" and "Indian Laburnum". It is of the large genus Senna and it belongs to the subfamily Caesalpiniaceae and the family Fabaceae (Sartorelli et al., 2009). Its origin is in the Indian subcontinent and is distributed in various tropical regions including Asia, South America, Australia and Africa (Orwa et al., 2009). Senna fistula L. (Fabaceae Caesalpiniodeae) a very common plant known for its medicinal properties is a semi wide in nature. Senna fistula (L.) is a deciduous, medium sized tree up to $24 \mathrm{~m}$ in height and $1.8 \mathrm{~m}$ in girth, cultivated almost throughout Indian. (Singh et al., 2013). The leaves and seeds are useful in leprosy, ringworm, flatulence colic, dyspepsia, constipation, cough, bronchitis, cardiac disorder. It flowers nearly all year round (August - June) and produces enormous amounts of seeds that do not germinate readily in nature, there is virtually no report of natural germination (regeneration) in cultivated population of Senna fistula. It was therefore of scientific interest to investigate natural seed germination (regeneration) if any, in cultivated population of Senna fistula. Seed dormancy in Senna fistula is a Widely investigated and Well documented aspect of the species from virtually all tropical regions; namely Babalola et al. (2014) in Nigeria.
Several experiments have been carried out to break the dormancy of the seeds in view of the fact that the species has many uses, in particular as an ornamental and medicinal plant. The cheapest and probably the most efficient method to break seed dormancy in the species is by immersion of the fresh seeds in hot water ( 80 to $100^{\circ} \mathrm{C}$ ) for about 2 to $5 \mathrm{~min}$ or in concentrated sulphuric acid for about 5 min (Babalola et al.,2014).

Sowing media are materials that plants grow in, specifically designed to support plant growth and can either be a solid or a liquid. Different components are blended to create homemade and commercial growing media and different types of growing media are used to cultivate various plants. Topsoil is the upper, outermost layer of soil, usually the top 5 inches (13 $\mathrm{cm})$ to 10 inches $(25 \mathrm{~cm})$. It has the highest concentration of organic matter and microorganisms and is where most of the earth's biological soil activity occurs. Topsoil is composed of mineral particles, organic matter, water, and air.

Organic matter varies in quantity on different soils. The strength of soil structure decreases with the presence of organic matter, creating weak bearing capacities. Organic matter condenses and settles in different ways under certain conditions, such as 
roadbeds and foundations. (Al-Menaie et al., 2010). Seed germination is affected by many factors such as: oxygen, water, temperature and in some cases light as well as germination media (Hartmann et al., 2001). However, the Senna fistula species is threatened with extinction from the natural habitat due to overexploitation. At the same time, this species is facing a regeneration problem mainly due to a low germination rate because of the hardness of the seed and a low fruit production. Senna fistula has various seed sizes with a very hard coat. Therefore, there is need to investigate the influence of sowing media on the germination of the species.

\section{MATERIALS AND METHODS}

The experiment was carried out at Federal College of Forestry Farm Practical Experimental site, Jericho Hill Ibadan, Oyo State, Nigeria. The area lies between the latitude of $7^{0} 26^{\circ} \mathrm{N}$ and longitude of $3^{0} 54^{\circ} \mathrm{E}$. The climatic condition of the area is tropically dominated by rainfall pattern from $1400 \mathrm{~mm}-1500 \mathrm{~mm}$. The average temperature is about $31.2^{\circ} \mathrm{C}$. The area experiences two distinct seasons which are dry season and rainy season usually commenced from November to March, while the rainy start April to October (FRIN Meteorological Station, 2020). Seed of Senna fistula L. was collected at Federal College of Forestry, Jericho Hill, Ibadan, Oyo State, Nigeria. The top soil used was collected from the College premises, the grinded coconut husk was collected at a nearby coconut market (Ogunpa market), and the weathered-sawdust was collected from Forestry Research Institute of Nigeria (FRIN), while the river sand was collected from stream within the college. Tools used were bucket, vernier caliper, measuring ruler, seed boxes.

The seed of Senna fistula L. was harvested from a mother tree. It was removed from the capsule and airdried and the seed boxes was filled with different sowing media such as top soil, river sand, grinded coconut husk, and weathered saw dust respectively, thirty (30) seeds of Senna Fistua L. was sown and watered.

The treatments were arranged in a completely randomized design (CRD) and replicated two times. Data collection commenced as soon as the seed emerged from the sowing media and continue weekly and at the end of germination the seedling was transplanted into a seven litter bucket filled with top soil and watered. The treatment was also arranged in a completely randomized design (CRD) replicated four times. Data was collected on growth parameters and these commence two weeks after transplanting and continue fortnightly thereafter. The experiment was terminated after three month.

\section{Experimental layout \\ Experiment I \\ T1 - Top Soil (TS)}

T2 - River Sand (RS)

T3 - Grinded Coconut Husk (GCH)

T4 - Weathered Saw Dust (WSD)

\begin{tabular}{llll}
\multicolumn{3}{c}{ Experiment II } & \\
$\mathrm{R}_{1} \mathrm{~T} 1$ & $\mathrm{R}_{2} \mathrm{~T}_{4}$ & $\mathrm{R}_{3} \mathrm{~T}_{3}$ & $\mathrm{R}_{4} \mathrm{~T}_{1}$ \\
$\mathrm{R}_{1} \mathrm{~T}_{2}$ & $\mathrm{R}_{2} \mathrm{~T} 1$ & $\mathrm{R}_{3} \mathrm{~T}_{2}$ & $\mathrm{R}_{4} \mathrm{~T}_{4}$ \\
$\mathrm{R}_{1} \mathrm{~T}_{3}$ & $\mathrm{R}_{2} \mathrm{~T}_{2}$ & $\mathrm{R}_{3} \mathrm{~T}_{4}$ & $\mathrm{R}_{4} \mathrm{~T}_{3}$ \\
$\mathrm{R}_{1} \mathrm{~T}_{4}$ & $\mathrm{R}_{2} \mathrm{~T}_{3}$ & $\mathrm{R}_{3} \mathrm{~T}_{1}$ & $\mathrm{R}_{4} \mathrm{~T}_{2}$
\end{tabular}

Data collection: Data was collected on the following parameters:

Emergence Percentage: this was the total number of seedling emergence over total number of seed planted multiply by 100 :

$\frac{\text { Total number of seedling emergence }}{\text { Total number of seed planted }} \times 100$

Days to 50\% emergence: This was done after half of the seeds planted emerged

Plant height $(\mathrm{cm})$ : this was done by using measuring ruler grand in centimeter to measure the height from the soil level to the top of terminal bud of the seedlings and recorded.

Collar diameter $(\mathrm{mm})$ : this was done by using venire caliper to measure the seedlings at $2 \mathrm{~cm}$ above the collar and recorded.

Number of Leaf: this was done by counting the number of leaves on each seedling and recorded.

Leaf area estimation $\left(\mathrm{cm}^{2}\right)$ : graph sheet was used for the estimation of leaf area and recorded.

Data analysis: Data generated was subjected to analysis of variance (ANOVA), while mean separation where appropriate was done using Least Significant Difference (LSD). The test was done at 5\% level of significance.

\section{RSULTS AND DISCUSSION}

The physicochemical properties of the soil used for planting was analyzed and data presented in table 1 . Data revealed that, the $\mathrm{pH}$ was near neutral at 6.27 . Table 2 shows that the seeds planted in river sand had the highest emergence percentage of $70 \%$, follow by the one planted in weathered sawdust with $40 \%$ and the least was from the seeds planted in grinded coconut husk and topsoil with $23 \%$ each. $50 \%$ emergence was achieved only by seeds planted in river sand fourthfour (44) days after planting. Table 3 shows the effect of growing media on number of leaves of Senna fistula seedlings for a period of ten week. At week ten, it was observed that seedling raised on river sand produced the highest number of leaves with an average value of 20.4, followed closely by seedlings raised on 
weathered sawdust (18.9). Seedlings raised on coconut grinded husk produced the least number of leaves with an average value of 14.5. Menaie et al. (2010) reported that plant height and number of leaves were higher and perform better in soil which contained different growing media.

Table 4 shows the effect of growing media on height of Senna fistula seedling for a period of ten weeks. The result reveals that seedling raised on top soil perform best with an average mean of $10.62 \mathrm{~cm}$. Seedlings raised on river sand perform second best in term of plant height with an average value of $10.35 \mathrm{~cm}$, while seedlings raised on grinded coconut husk performed least with an average value of $8.50 \mathrm{~cm}$. According to Sekepe (2013), he reported that plant height of Senna fistula was the only parameters which significantly increased by river sand and top soil, while other growth parameters were not influenced by growth media. Menaie et al., (2010) reported that plant height and number of leaves were higher in soil mixture which contained different growing media.

Table 1: physiochemical analysis of the soil used for planting

\begin{tabular}{ll}
\hline Nutrient & Soil (qty) \\
\hline $\mathrm{pH}(\mathrm{H} 20)$ & 6.27 \\
Organic Carbon (OC) & 0.56 \\
Organic Mineral (M) & 0.96 \\
$\mathrm{~T} . \mathrm{N}$ & 0.05 \\
$\mathrm{Na}(\mathrm{cmol} / \mathrm{kg})$ & 1.37 \\
$\mathrm{Ca}$ & 1.40 \\
Magnesium $(\mathrm{Mg})$ & 2.5 \\
$\mathrm{~K}(\mathrm{cmol} / \mathrm{kg})$ & 0.06 \\
$\mathrm{Iron}(\mathrm{Fe})$ & 120 \\
$\mathrm{Cu}$ & 1.5 \\
$\mathrm{Mn}$ & 210 \\
$\mathrm{Zn}$ & 13 \\
Potassium $(\mathrm{P})$ & 0.16 \\
Sand\% & 74.5 \\
Clay\% & 15 \\
Silt\% & 10.5 \\
\hline
\end{tabular}

Table 2: Effect of different sowing media on emergence percentage $(\%)$

\begin{tabular}{ll}
\multicolumn{2}{c}{ percentage $(\%)$} \\
\hline Treatment & Emergence percentage \\
\hline Top soil & $23 \%$ \\
River sand & $70 \%$ \\
Grinded coconut husk & $23 \%$ \\
Weathered saw dust & $40 \%$ \\
\hline
\end{tabular}

Table 3: The effect of different growing media on number of leaves of Senna fistula seedlings

\begin{tabular}{llllll}
\hline Treatment & $\mathbf{2}$ & $\mathbf{4}$ & $\mathbf{6}$ & $\mathbf{8}$ & $\mathbf{1 0}$ \\
\hline T1 & 9.50 & 10.50 & 12.20 & 14.6 & 16.3 \\
T2 & 11.50 & 12.20 & 14.20 & 17.3 & 20.4 \\
T3 & 6.50 & 7.20 & 9.20 & 11.40 & 14.5 \\
T4 & 8.50 & 10.8 & 13.40 & 15.2 & 18.9 \\
LSD & 5.80 & 7.13 & 5.69 & 8.35 & 7.2 \\
\%CV & 44.3 & 53.3 & 46.6 & 30.2 & 24.2 \\
\hline
\end{tabular}

Table 4: Effect of growing media on plant height $(\mathrm{cm})$ of Senna

\begin{tabular}{llllll}
\multicolumn{7}{c}{ fistula seedlings } \\
\hline Treatment & $\mathbf{2}$ & $\mathbf{4}$ & $\mathbf{6}$ & $\mathbf{8}$ & $\mathbf{1 0}$ \\
\hline T1 & 7.65 & 8.18 & 9.00 & 9.85 & 10.62 \\
T2 & 8.20 & 8.80 & 9.38 & 9.80 & 10.35 \\
T3 & 5.95 & 5.90 & 6.20 & 7.85 & 8.50 \\
T4 & 8.50 & 8.80 & 9.20 & 9.62 & 10.05 \\
LSD & 4.31 & 3.0 & 3.04 & 2.69 & 2.61 \\
\%CV & 38.2 & 25.4 & 23.6 & 19.6 & 17.6 \\
\hline
\end{tabular}

Table 5: Effect of growing media on stem diameter (mm) of Senna

\begin{tabular}{llllll}
\multicolumn{7}{c}{ fistula seedlings } \\
\hline Treatment & $\mathbf{2}$ & $\mathbf{4}$ & $\mathbf{6}$ & $\mathbf{8}$ & $\mathbf{1 0}$ \\
\hline T1 & 0.43 & 0.67 & 0.68 & 0.69 & 0.71 \\
T2 & 0.45 & 0.67 & 0.68 & 0.70 & 0.73 \\
T3 & 0.42 & 0.62 & 0.65 & 0.67 & 0.69 \\
T4 & 0.47 & 0.69 & 0.70 & 0.76 & 0.79 \\
LSD & 0.16 & 0.12 & 0.07 & 0.10 & 0.11 \\
\%CV & 23.3 & 11.3 & 7.1 & 9.2 & 10.4 \\
\hline
\end{tabular}

It was observed from table 5 that seedling raised on weathered sawdust performed best in stem diameter with an average value of $0.79 \mathrm{~mm}$. This was followed by seedling raised on river sand with an average value of $0.73 \mathrm{~mm}$, seedling raised on grinded coconut husk had the least performance with an average value of $0.69 \mathrm{~mm}$. Menaie, et al., (2010) observed similar result when sand was used as a germinating media. According to them, germination and seedlings growth were best when seeds are soaked in water and germinated in sand, coconut coir and weathered sawdust which gave maximum seedlings height, stem girth, root length, and percentage of germination.

Table 6: Effect of growing media on leaf area $\left(\mathrm{cm}^{2}\right)$ increase of

\begin{tabular}{llllll}
\multicolumn{7}{c}{ Senna fistula seedlings } \\
\hline Treatment & $\mathbf{2}$ & $\mathbf{4}$ & $\mathbf{6}$ & $\mathbf{8}$ & $\mathbf{1 0}$ \\
\hline T1 & 3.48 & 4.66 & 16.03 & 28.51 & 37.14 \\
T2 & 1.80 & 6.37 & 11.41 & 21.92 & 30.32 \\
T3 & 1.78 & 3.95 & 10.72 & 21.91 & 29.50 \\
T4 & 1.95 & 7.42 & 13.28 & 24.09 & 35.08 \\
LSD & 1.97 & 3.62 & 5.41 & 6.63 & 8.04 \\
\%CV & 21.9 & 20.0 & 21.6 & 19.4 & 22.4 \\
\hline
\end{tabular}

Table 6 shows the effect of growing media on leaf area of Senna fistula seedlings. It was evident from the table that seedlings raised on top soil produce the highest leaf area with an average value of $37.14 \mathrm{~cm}^{2}$. Seedling raised on weathered sawdust performed second best in leaf area with an average value of $35.08 \mathrm{~cm}^{2}$, while seedlings raised on coconut husk performed least with an average mean of $29.50 \mathrm{~cm}^{2}$. This is in line with Menaie et al., (2010), who reported that leaf area were higher in soil mixture which contained different growing media.

Conclusion: It was concluded that the different sowing media used had positive effect on the seed emergence. The seeds planted in river sand had the highest emergence percentage of $70 \%$, while the different sowing media used did not have any significant effect on the vegetative growth parameters. Statistically, they had same effect on the parameters measured. Nonetheless, seedlings from river sand produced highest number of leave (20.4), seedlings from topsoil produced highest plant height and largest leaf area $10.62 \mathrm{~cm}$ and $37.14 \mathrm{~cm}^{2}$ respectively. The seedlings from weathered saw dust produced the widest stem girth $0.79 \mathrm{~mm}$, while seedlings from grinded coconut husk had lowest values for all the growth parameters measure. It is therefore recommended that horticulturist or nursery men that want to propagate Senna fistula seed should use river sand. Senna fistula 
seed should be pre-treated before planting to aid prompt emergence and healthy growth.

\section{REFERENCES}

Al-Menaie, H.S., Ragam, O., Shatti, A., Mathew, M., Suresh, N. (2010). The Effects of different Treatments on Seed Germination of the Senna Fistula L. and Senna Nodosa

Babalola, S.E., Shonubi, O. O., Okusanya, O. T. (2014) Seed Dormancy in Senna Fistula Population from Nigeria. Journals. Am. Sci 10(1):86-93.

Hartmann, H.T., Kester, D.E., Davies, F.T., Greeve, R.L., (2001) Principles and Practices of Plant Propagation. 6th Edn., Prentice Hall Publishers, London.

Menaie, H. S., Ragom, O., Shatti, A., Mathew, M., Suresh, N. (2010). Evaluating the Growth Performance of Cassia Nodosa and Cassia Fistula L. Seedlings using different Potting Mixtures. Academic Journal of Plant Sciences, 3(1), 33-36.
Orwa C, I., Iutua, A, Kindt, R. J., Amnadass, R., Simons, A. (2009). Agroforestry Database: A Tree Reference and Selection Guide. http://www.worldagroforestry.org/af/treedb/

Sartorelli, P., Carvalho, C. S., Reimao, I. Q., Ferreira, M. I. P., Tempone, A. G. (2009). Antiparasitic Activity of Biochanin A. An Isolated Isoflavone from Fruits of Senna Fistula (Leguminosae). Paras. Res. 104:311-314.

Singh S., and Yadav A. (2013) A Review on Senna Species: Pharmacological, Traditional and Medicinal Aspect in various Countries. Ame. Journal of Phyromea' anna' $C h^{\prime}$ therapeutic; 1(3): 291-312:2013.

Sekepe, L., Thembinkosi, M., Witness, M. (2013). Evaluating the Growth Response of Cassia Abbreviata Oliv. Seedlings to Growing Media in Botswana. Research Journal of Agriculture and Forestry Science, I (10), I 0-14. 